\title{
Overweight, obesity and other risk factors for IHD in Brazilian schoolchildren
}

\author{
Sandra Mari Barbiero ${ }^{1, *}$, Lucia Campos Pellanda ${ }^{1, *}$, Claudia Ciceri Cesa ${ }^{1}$, \\ Paula Campagnolo ${ }^{2}$, Flávia Beltrami ${ }^{2}$ and Caroline $C$ Abrantes ${ }^{2}$ \\ 'Institute of Cardiology of Rio Grande do Sul/Cardiology Universitary Foundation, Av. Princesa Isabel, \\ 370 Santana Porto Alegre, RS 90620-001, Brazil: ${ }^{2}$ Federal University, Foundation of Health Sciences, \\ Porto Alegre, Brazil
}

Submitted 10 April 2007: Accepted 9 June 2008: First published online 23 July 2008

\begin{abstract}
Objective: To estimate the prevalence of overweight, obesity and nutritional habits in schoolchildren aged 10-18 years.

Methods: Contemporary, cross-sectional, population-based study, with a stratified probabilistic sample of secondary schools in Porto Alegre comprising a total of 511 schoolchildren. Data on family risk factors, anthropometrics and eating habits were collected.

Results: The prevalence of excess weight was $27 \cdot 6 \%$ among the schoolchildren, with $17 \cdot 8 \%$ being overweight (BMI $\geq 85$ th and $<95$ th percentile) and $9 \cdot 8 \%$ obese $(\mathrm{BMI} \geq 95$ th percentile). Overweight was more prevalent in females (19.9\%) and obesity in males $(11 \cdot 8 \%)$. Children who ate fewer meals per day tend to be more obese (mean: $3 \cdot 51$ (SD 1.14) v. 4.22 (SD 1.01) meals/d for students with normal weight). The mean weekly intake of unhealthy foods was $3 \cdot 25$ times for soft drinks, 2.91 for fried foods and 4.01 for sweets. The intake of skimmed milk $(38.9 \%)$ and diet soft drinks (20.9\%) was greater among obese children.

Conclusion: Overweight and obesity are increasing even in developing countries such as Brazil. Although many families are already taking measures towards healthier health habits, preventive actions must be considered a priority, with an emphasis on education, in order to avoid the need to treat obesity and its significant burden in the near future.
\end{abstract}

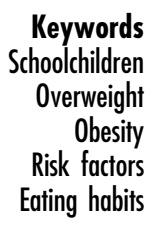

According to data from the WHO, about one-third of deaths worldwide are due to circulatory diseases such as coronary artery disease and cerebrovascular disease ${ }^{(1)}$. Approximately $80 \%$ of deaths from CVD occur in developing countries and it is estimated that by 2010 these diseases will be the main cause of death in those countries ${ }^{(2)}$.

Atherosclerotic disease is the result of a combination of genetic, socio-economic and environmental factors. Pathological alterations due to atherosclerosis may be identified long before the onset of clinical signs of the disease. By the end of adolescence, about $61 \%$ of individuals present some type of atherosclerotic lesion in the coronary arteries. After the age of 40 years, such lesions are present in almost $95 \%$ of the population.

Lifestyles causing atherosclerosis may begin in early childhood and the prevalence of risk factors such as overweight and obesity, hypertension, dyslipidaemia, sedentarism and diabetes mellitus in this age group has been rising. If these conditions persist, it is likely that diseases that were formerly seen only in much older adults will become a cause of morbidity in young adults and adolescents as well. It is therefore necessary to institute early preventive management at all levels of health care.

Considering the evidence that the prevalence of overweight and obesity has been increasing in developing countries, including $\mathrm{Brazil}^{(3)}$, the purpose of the current study was to investigate the presence of these risk factors in a population-based sample of schoolchildren aged 10 to 18 years in Porto Alegre, southern Brazil. In addition, we sought to examine eating habits including the consumption of healthy foods and foods with a high fat content.

\section{Methods}

A population-based, cross-sectional study was conducted, with a probabilistic sample of 10- to 18-year-old schoolchildren selected by conglomerates from all municipal, state and federal public schools of basic education in Porto Alegre. The project was approved by the ethics committee of the Institute of Cardiology of Rio Grande do Sul. All schools were contacted about the project, and 
details about the planned activities and the study goals were explained to the principal and teachers. In the six randomly selected schools, 699 students were eligible; we obtained consent for 513. Two students were excluded due to chronic renal disease and significant growth retardation (one case) and myelomeningocele (one case).

After informed consent from parents or guardians and the child, the parents received a questionnaire about the family history. After this questionnaire was returned, children were assessed at school. This evaluation consisted of another self-applied questionnaire, completed by the child, with questions on daily physical activities; a questionnaire on food intake; and a physical assessment.

The physical assessment included physical examination of the cardiovascular system, with cardiac auscultation, and measurements of blood pressure, height weight, skinfold thickness, and waist and hip circumferences as follows ${ }^{(4)}$.

1. Aneroid mercury sphygmomanometers were used to measure blood pressure, using manometers with graduations from 0 to $300 \mathrm{mmHg}$. The pressures were categorized into percentiles according to the report of the Second Task Force on Blood Pressure Control in Children $^{(5)}$

2. Weight was measured with a portable electronic balance with a capacity up to $120 \mathrm{~kg}$.

3. Height was measured using a $2 \mathrm{~m}$ metallic measuring tape with $0 \cdot 1 \mathrm{~cm}$ markings, attached to a wall painted a single colour, with the children standing erect during maximum inhalation.

4. BMI cut-off points for overweight $(\geq 85$ th and $<95$ th percentile) and obesity ( $\geq 95$ th percentile) were based on the reference curve of the US National Center for Health Statistics (NCHS) and the WHO criteria ${ }^{(6)}$.

\section{Statistical analyses}

Analyses were performed using the statistical software packages SPSS version $11 \cdot 0$ (SPSS Inc., Chicago, IL USA) and STATA version $7 \cdot 0$ (Stata Corporation, College Station, TX, USA; for survey estimations). It was estimated that for a prevalence of $15.0 \%(95 \%$ CI $11.5,18.5 \%)$ of overweight or obesity, with a confidence level of $95 \%$, it would be necessary to study 398 schoolchildren. Thirty per cent was added to this value, considering the sampling by conglomerates, adding up to a total number needed estimated at 517 schoolchildren.

Prevalences are described with respective 95\% confidence intervals. The continuous variables are described by means, standard deviations and survey-adjusted confidence intervals. ANOVA was used for BMI categorized into three groups (normal, obese and overweight). The Pearson correlation was used to assess correlations between continuous variables.

Additionally, the overweight and obesity groups were merged, and the differences between the groups with and without excess weight were assessed using the
Student $t$ test or Mann-Whitney $U$ test for continuous variables and the $\chi^{2}$ or Fisher's exact test for categorical variables. A $5 \%$ level of significance was considered in all comparisons.

\section{Results}

Five hundred and eleven schoolchildren from six randomly selected schools were studied, with a mean age of 12.57 years, $44 \cdot 8 \%$ ( $n$ 229) male and $55 \cdot 2 \%(n$ 282) female. Table 1 shows the general characteristics of the sample. The proportion of families with parents with less than 8 years of schooling was $47.0 \%$ for fathers and $52 \cdot 4 \%$ for mothers.

Family history of risk factors for CVD in first-degree relatives included obesity in $12.7 \%$, dyslipidaemia in $16.8 \%$, diabetes in $6.7 \%$, hypertension in $28.0 \%$ and CVD or ischaemia in $1.4 \%$. The mean number of relatives with risk factors was 1.6 for obese family members, 1.3 for dyslipidaemia, 1.3 for diabetes, 1.6 for hypertension and 1.3 for history of an ischaemic event. The mean BMI of the parents was 26.5 (SD $4 \cdot 0) \mathrm{kg} / \mathrm{m}^{2}$ for the fathers and $25 \cdot 7(\mathrm{sD} 5 \cdot 8) \mathrm{kg} / \mathrm{m}^{2}$ for the mothers.

The prevalence of excess weight (BMI $\geq 85$ th percentile) was $27 \cdot 6 \%$ (95\% CI $22 \cdot 2,33 \cdot 9 \%$; 141 students), including $17 \cdot 8 \%$ (95\% CI $13 \cdot 8,22 \cdot 8 \%$; ninety students) who were overweight (BMI $\geq 85$ th and $<95$ th percentile) and $9 \cdot 8 \%$ (95\% CI 7.0, 13.6\%; fifty students) who were obese (BMI $\geq 95$ th percentile). Overweight was more prevalent in females (19.9\%) and obesity in males (11.8\%; Table 2). Proportions of overweight and obesity in different age groups are shown in Fig. 1.

Regarding eating habits, $74.6 \%$ of the participants reported consuming four or more meals daily. The proportion who did not eat breakfast among respondents was $32 \cdot 2 \%$ (141 participants).

Mean intake was four or more times weekly for all healthy foods questioned (fruits, vegetables, meat and

Table 1 General characteristics of the studied population: schoolchildren aged 10-18 years, Porto Alegre, Brazil ( $n$ 511)

\begin{tabular}{lrr}
\hline Variable & $n$ & $\%$ \\
\hline Male & 229 & $44 \cdot 8$ \\
Female & 282 & $55 \cdot 2$ \\
Age & & \\
$\quad \leq 13$ years & 377 & $73 \cdot 8$ \\
$\quad 14$ years & 134 & $26 \cdot 2$ \\
Siblings & & \\
$\quad$ None & 62 & $12 \cdot 7$ \\
$\quad$ i1 & 425 & $87 \cdot 3$ \\
First-degree relative with & & \\
$\quad$ Obesity & 62 & $12 \cdot 7$ \\
$\quad$ Dyslipidaemia & 86 & $16 \cdot 8$ \\
$\quad$ Diabetes & 34 & $6 \cdot 7$ \\
$\quad$ Hypertension & 143 & $28 \cdot 0$ \\
$\quad$ History of ischaemic event & 7 & $1 \cdot 4$ \\
Passive smoking & 264 & $54 \cdot 2$ \\
\hline & & \\
\hline
\end{tabular}


Table 2 Excess weight according to gender: schoolchildren aged 10-18 years, Porto Alegre, Brazil ( $n$ 511)

\begin{tabular}{|c|c|c|c|c|c|c|c|c|c|}
\hline & \multicolumn{3}{|c|}{ Weight excess } & \multicolumn{3}{|c|}{ Overweight } & \multicolumn{3}{|c|}{ Obesity } \\
\hline & $n$ & $\%$ & $95 \% \mathrm{Cl}$ & $n$ & $\%$ & $95 \% \mathrm{Cl}$ & $n$ & $\%$ & $95 \% \mathrm{Cl}$ \\
\hline Male & 62 & $27 \cdot 1$ & $19 \cdot 7,35 \cdot 7$ & 35 & $15 \cdot 3$ & $10 \cdot 0,22 \cdot 4$ & 27 & $11 \cdot 8$ & $7 \cdot 8,17 \cdot 3$ \\
\hline Female & 79 & $28 \cdot 0$ & $22 \cdot 8,34 \cdot 3$ & 56 & $19 \cdot 9$ & $15 \cdot 8,25 \cdot 0$ & 23 & $8 \cdot 2$ & $5 \cdot 9,11 \cdot 3$ \\
\hline Total & 141 & $27 \cdot 6$ & $22 \cdot 2,33.9$ & 91 & $17 \cdot 8$ & $13 \cdot 8,22 \cdot 8$ & 50 & $9 \cdot \overline{8}$ & $7 \cdot 0,13 \cdot 6$ \\
\hline
\end{tabular}

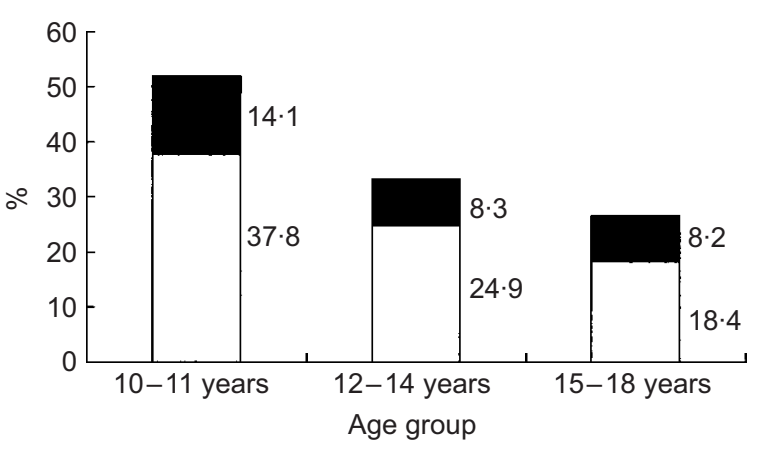

Fig. 1 Proportions of overweight $(\square)$ and obesity ( $\square$ ) in different age groups: schoolchildren aged $10-18$ years, Porto Alegre, Brazil

dairy products), with the exception of vegetables. Concerning non-healthy foods, the mean weekly consumption was $3 \cdot 25$ times for soft drinks, $2 \cdot 91$ times for fried foods and $4 \cdot 01$ times for sweets (Table 3 ). Table 4 shows the comparison of eating habits among schoolchildren with excess and normal weight.

Table 5 shows that obese children ate fewer meals per day (mean $3.51(\mathrm{SD} 1 \cdot 14)$ meals/d) than overweight $(3.72$ (SD 1·11)) and normal weight $(4 \cdot 22$ (SD 1·01)) students. These differences were greater in girls. Among girls with excess weight, $47 \cdot 2 \%$ ate fewer than four meals a day, compared with $21 \cdot 0 \%$ of the girls with normal weight $(P=0 \cdot 005)$. Among boys, these proportions were $36 \cdot 0 \%$ and $17 \cdot 8 \%$, respectively $(P=0.095)$. Obese children reported more frequent use of skimmed milk (38.9\%) and diet soft drinks (20.0\%). Among the obese schoolchildren studied, $23.9 \%$ were the only child in the family and $19 \cdot 1 \%$ were born prematurely. Obese and overweight children had more first-degree relatives who were obese.

Correlations between the children's and parents' BMI were weak but significant, both for the father $(r=0 \cdot 19$, $P<0 \cdot 001)$ and the mother $(r=0 \cdot 29, P<0 \cdot 001)$. Table 6 describes the proportions of obesity and overweight according to the parents' BMI categories. The mean BMI was $19 \cdot 2$ (sD 2.9), 20.5 (sD 3.5) and $20.9(\mathrm{sD} 3.8) \mathrm{kg} / \mathrm{m}^{2}$ for the fathers and $19 \cdot 5$ (SD 3.1), 21.0 (SD 3.4) and 20.9 (SD $3 \cdot 8) \mathrm{kg} / \mathrm{m}^{2}$ for the mothers of normal weight, overweight and obese children, respectively. Additionally, when one of the parents had excess weight, the prevalence ratio for excess weight in the child was 1.9 . When both parents had excess weight, the prevalence ratio increased to $2 \cdot 5$ (Table 7).
Table 3 Mean weekly consumption of selected foods: schoolchildren aged 10-18 years, Porto Alegre, Brazil

\begin{tabular}{lll}
\hline Food & Mean & $95 \% \mathrm{Cl}$ \\
\hline Fruits & $4 \cdot 16$ & $3 \cdot 7,4 \cdot 6$ \\
Vegetables & $3 \cdot 69$ & $3 \cdot 3,4 \cdot 1$ \\
Meats & $4 \cdot 76$ & $4 \cdot 4,5 \cdot 1$ \\
Milk products & $5 \cdot 11$ & $2 \cdot 9,3 \cdot 6$ \\
Soft drinks & $3 \cdot 25$ & $2 \cdot 7,3 \cdot 1$ \\
Fried foods & $2 \cdot 91$ & $3 \cdot 3,4 \cdot 6$ \\
Sweets & $4 \cdot 01$ & $4 \cdot 7,5 \cdot 5$ \\
\hline
\end{tabular}

\section{Discussion}

In the present cross-sectional population-based study in Porto Alegre, a large state capital in south Brazil, significant prevalences of overweight and obesity were observed among both male and female schoolchildren. These results are similar to studies undertaken in other Brazilian state capitals: in Sao Paulo ${ }^{(7)}$ and Recife ${ }^{(8)}$ schoolchildren, the prevalence of excess weight was $24.0 \%$ and $21.8 \%$, respectively; in Rio de Janeiro ${ }^{(9)}$ it was $22 \cdot 4 \%$ for boys and $24.5 \%$ for girls; and in Salvador ${ }^{(10)}$ the prevalence of obesity (BMI $\geq 95$ th percentile) was $15 \cdot 8 \%$.

This information is relevant in the light of other studies reporting risk factors for the development of atherosclerotic diseases in this age group worldwide. The results of the Bogalusa Heart Study ${ }^{(11)}$ and The Pathobiological Determinants of Atherosclerosis in Youth ${ }^{(12)}$ study, based on autopsies of the aorta and coronary arteries of individuals aged 6 to 30 years, confirmed the presence of atherosclerotic lesions, and showed that lesion size increased with age and with the presence and intensity of risk factors such as dyslipidaemias, smoking and hypertension. These studies supported previous hypotheses that these risk factors are related to the development of atherosclerosis, and emphasized the need for prevention of CVD early in life. The significant presence of risk factors among first-degree relatives found in the population of the present study supports concerns about the family lifestyle that is reproduced by children and teenagers.

The high percentage of schoolchildren who habitually eat less healthy foods is in accordance with a Brazilian national survey of family food intake undertaken in $2002-3^{(13)}$, which reported a growth of about $400 \%$ in the consumption of selected foods such as sweets, cookies and soft drinks. Besides overall changes in lifestyle 
Table 4 Habitual consumption* of selected food groups according to weight category: schoolchildren aged 10-18 years, Porto Alegre, Brazil

\begin{tabular}{|c|c|c|c|c|c|c|c|}
\hline \multirow[b]{2}{*}{ Food } & \multicolumn{2}{|c|}{ Normal weight ( $n$ 370) } & \multicolumn{2}{|c|}{ Overweight ( $n$ 91) } & \multicolumn{2}{|c|}{ Obese $(n 50)$} & \multirow[b]{2}{*}{$P$} \\
\hline & $n$ & $\%$ & $n$ & $\%$ & $n$ & $\%$ & \\
\hline Sweets & 185 & $51 \cdot 2$ & 31 & $34 \cdot 8$ & 15 & $31 \cdot 3$ & 0.04 \\
\hline Fried foods & 90 & $28 \cdot 8$ & 18 & $26 \cdot 1$ & 3 & $7 \cdot 7$ & 0.02 \\
\hline Milk products & 225 & $69 \cdot 4$ & 47 & $64 \cdot 4$ & 23 & $53 \cdot 5$ & 0.38 \\
\hline Fruits & 186 & $51 \cdot 1$ & 50 & $54 \cdot 9$ & 28 & $56 \cdot 0$ & 0.72 \\
\hline Soft drinks & 128 & $35 \cdot 0$ & 27 & $30 \cdot 0$ & 18 & $36 \cdot 7$ & 0.58 \\
\hline Vegetables & 187 & $50 \cdot 8$ & 37 & $41 \cdot 1$ & 29 & $58 \cdot 0$ & 0.23 \\
\hline
\end{tabular}

*Habitual consumption: four or more times weekly.

Table 5 Dietary habits and family characteristics according to weight category: schoolchildren aged 10-18 years, Porto Alegre, Brazil

\begin{tabular}{|c|c|c|c|c|c|c|c|}
\hline \multirow[b]{2}{*}{ Variable } & \multicolumn{2}{|c|}{ Normal weight ( $n$ 370) } & \multicolumn{2}{|c|}{ Overweight ( $n$ 91) } & \multicolumn{2}{|c|}{ Obese $(n 50)$} & \multirow[b]{2}{*}{$P^{*}$} \\
\hline & Mean & SD & Mean & SD & Mean & SD & \\
\hline \multirow[t]{2}{*}{ No. of meals/d } & $4 \cdot 22$ & $1 \cdot 01$ & $3 \cdot 72$ & $1 \cdot 11$ & $3 \cdot 51$ & $1 \cdot 14$ & 0.005 \\
\hline & $n$ & $\%$ & $n$ & $\%$ & $n$ & $\%$ & \\
\hline \multicolumn{7}{|l|}{ Soft drinks } & $0 \cdot 163$ \\
\hline Normal & 296 & $94 \cdot 6$ & 68 & $94 \cdot 4$ & 32 & $80 \cdot 0$ & 0.01 \\
\hline Diet & 16 & $5 \cdot 1$ & 4 & $5 \cdot 6$ & 8 & $20 \cdot 0$ & \\
\hline \multicolumn{8}{|l|}{ Milk } \\
\hline Whole fat & 276 & $91 \cdot 7$ & 61 & $89 \cdot 7$ & 22 & $61 \cdot 1$ & 0.08 \\
\hline Skimmed & 25 & $8 \cdot 3$ & 7 & $10 \cdot 3$ & 14 & $38 \cdot 9$ & \\
\hline Only child & 39 & $11 \cdot 0$ & 12 & $13 \cdot 6$ & 11 & $23 \cdot 9$ & $0 \cdot 112$ \\
\hline Premature birth & 38 & $11 \cdot 7$ & 10 & $12 \cdot 2$ & 9 & $19 \cdot 1$ & 0.316 \\
\hline \multicolumn{8}{|l|}{ Age } \\
\hline$\leq 13$ years & 264 & $71 \cdot 5$ & 71 & $78 \cdot 0$ & 42 & $84 \cdot 0$ & 0.027 \\
\hline$>14$ years & 105 & $28 \cdot 5$ & 20 & $22 \cdot 0$ & 8 & $16 \cdot 0$ & \\
\hline \multicolumn{8}{|c|}{ First-degree relative with } \\
\hline Obesity & 47 & $12 \cdot 7$ & 17 & $18 \cdot 7$ & 12 & $24 \cdot 0$ & 0.042 \\
\hline Dyslipidaemia & 61 & $16 \cdot 5$ & 14 & $15 \cdot 4$ & 12 & $24 \cdot 0$ & 0.574 \\
\hline Diabetes & 20 & $5 \cdot 4$ & 11 & $12 \cdot 1$ & 5 & $10 \cdot 0$ & 0.058 \\
\hline Hypertension & 105 & $28 \cdot 5$ & 24 & $26 \cdot 4$ & 17 & $34 \cdot 0$ & 0.744 \\
\hline Ischaemic event & 4 & $1 \cdot 1$ & 3 & $3 \cdot 3$ & 0 & - & 0.369 \\
\hline
\end{tabular}

${ }^{\star} P$ for comparison between excess weight and normal weight.

Table 6 Children's weight categories according to parent's BMI: schoolchildren aged $10-18$ years, Porto Alegre, Brazil

\begin{tabular}{lccr}
\hline & \multicolumn{3}{c}{ Children (\%) } \\
\cline { 2 - 4 } & Normal weight & Overweight & Obese \\
\hline Father & & & \\
$\quad$ Normal weight & $80 \cdot 5$ & $15 \cdot 2$ & $4 \cdot 3$ \\
Overweight & $70 \cdot 8$ & $16 \cdot 1$ & $13 \cdot 1$ \\
Obesity & $63 \cdot 8$ & $20 \cdot 3$ & $15 \cdot 9$ \\
$\quad$ Morbidly obese & $100 \cdot 0$ & $0 \cdot 0$ & $0 \cdot 0$ \\
Mother & $78 \cdot 0$ & $15 \cdot 7$ & $6 \cdot 3$ \\
$\quad$ Normal weight & $63 \cdot 8$ & $23 \cdot 1$ & $13 \cdot 1$ \\
Overweight & $70 \cdot 3$ & $17 \cdot 6$ & $12 \cdot 2$ \\
Obesity & $25 \cdot 0$ & $25 \cdot 0$ & $50 \cdot 0$ \\
$\quad$ Morbidly obese & & & \\
\hline
\end{tabular}

among the Brazilian population, this increase may have occurred because of massive advertising for new brands of salty snacks and sweets launched by the food industry. A Brazilian study ${ }^{(14)}$ reported that $60 \%$ of the food products advertised on television belonged to the groups of
Table 7 Prevalence ratios (PR) of excess weight for children according to the number of parents with excess weight: schoolchildren aged 10-18 years, Porto Alegre, Brazil

\begin{tabular}{lccc}
\hline $\begin{array}{l}\text { No. of parents with } \\
\text { excess weight }\end{array}$ & $\begin{array}{c}\text { Children with } \\
\text { excess weight (\%) }\end{array}$ & PR & $95 \% \mathrm{Cl}$ \\
\hline None & $14 \cdot 6$ & 1.00 & reference \\
1 & $27 \cdot 7$ & 1.90 & $1 \cdot 09,3 \cdot 29$ \\
2 & $36 \cdot 5$ & $2 \cdot 50$ & $1 \cdot 43,4.39$ \\
\hline
\end{tabular}

fats, oils and sweets, with a total absence of advertising involving fruits and vegetables.

This increased consumption of non-healthy foods represents a profound change in the nutritional quality of the population, especially of children and adolescents: foods rich in fibre, vitamins and minerals (fruits and juices) have been replaced by soft drinks and sweets, and balanced meals by fatty snacks (fried foods and salty appetizers). In consequence, we have children and adolescents who, although overweight, qualitatively are malnourished. 
The introduction of fast-food restaurants, especially during the 1990s, introduced habits in Brazil that compromised the traditional eating pattern, replacing meals by quick snacks with high fat and sugar content ${ }^{(15)}$. These observations also raise the issue of the social and cultural value of industrialized/processed snacks and foods for each social group. Possibly Brazilian adolescents see this type of food as a factor of social and cultural inclusion, similar to smoking and other group behaviours; but in this particular case a greater income enables these types of food to be bought in families that one or to generations ago may have even suffered from undernutrition for socio-economic reasons.

The high percentage of obese students who were the only children or were born prematurely suggests that overfeeding could be a form of protection, love or even anxiety or compensation by the parents.

Another noteworthy aspect of the present study is the familial aggregation of excessive weight and other risk factors. There was a major association between the presence of overweight and obesity, especially among the mothers, and excess weight in their offspring. This highlights the importance of family-oriented interventions as a whole and not only oriented to a single member.

The classification of excess weight based on the reference curve of the NCHS and the WHO criteria ${ }^{(6)}$ of international BMI standards, with adiposity at $\geq 85$ th and $\geq 95$ th percentiles to define overweight and obesity respectively, is appropriate for population studies and therefore was used in the present investigation. Other methods, like those based on skinfold thickness, imply that sexual maturity of the schoolchildren should be taken into account while waist circumference measurements are not yet well standardized for children. In our study we decided to use the simplest method for clinical application, i.e. measuring weight and height to calculate BMI. The results would then be easier to use in routine health services and schools, responsible for the initial assessment of children and adolescents.

Some limitations of our study merit discussion. Since it is a cross-sectional study, without longitudinal follow-up, it is impossible to establish a temporal relationship between eating habits and excess weight. In the study, reverse causality in particular probably could have accounted for the finding of healthier eating patterns among schoolchildren with excess weight. Nevertheless, this result could represent a positive aspect, showing that the families are already aware of the problem and have been taking steps towards changing habits. Or, conversely, the obese adolescents who are already aware of advice on weight control and a healthy diet could have answered the questionnaires in a way they considered appropriate for this behaviour. Some behaviour modifications appear to be stronger among girls, possibly reflecting greater concern with the body image in this group.
The high prevalence of obesity and overweight in schoolchildren seen in the present study shows the need for preventive strategies at several levels. Overweight and obesity should represent a priority in preventive actions, emphasizing population education, and including several actions such as activities in schools for students and their families concerning the promotion of healthy weight and a balanced diet, controlling the advertising of non-healthy foods and their sale in school canteens, and continuous programmes to encourage physical activity among the students and their families.

In Porto Alegre, where the study was performed, two municipal laws were approved in 2006 involving diet control and education strategies for schools and children. One of them instituted the Month for Preventive Health Care in Child Obesity (no. 0838/06), including medical tests, fostering physical activity and educative actions for schoolchildren, parents and carers, teachers and other staff. The second municipal law established rules relating to food and beverages offered at canteens in public and private schools (no. 1455/02), controlling sugar, salt and fat, and prioritizing healthy foods.

The purpose of all these actions is to prevent the need to treat obesity and its consequences in the near future. Population-based studies that diagnose the local reality, such as the present study, can provide a basis for better planning of these strategies.

\section{Acknowledgements}

There were no external sources of funding for the current work and no conflicts of interest.

Authorship responsibilities: S.M.B. - conception and design, data acquisition and review, data interpretation, preparation of the manuscript; L.C.P. - conception and design, supervision of data collection, statistical analysis and interpretation, review of the manuscript; C.C.C., P.C., F.B. and C.C.A. - conception and design, data acquisition, technical support, review of the manuscript.

\section{References}

1. National Cholesterol Education Program (1992) Highlights of the report of the Expert Panel on Blood Cholesterol Levels in Children and Adolescents. Pediatrics 89, 495-501.

2. Puska P, Waxman A \& Porter D (2003) The Global Strategy on Diet, Physical Activity and Health. Geneva: WHO.

3. Balaban G \& Silva GAP (2001) Overweight and obesity prevalence in children and adolescents from a private school in Recife. J Pediatr 77, 96-100.

4. Heyward VH \& Stolarczyk LM (1996) Applied Body Composition Assessment. Champaign, IL: Human Kinetics.

5. National High Blood Pressure Education Program Working Group on Hypertension Control in Children and Adolescents (1996) Update on the 1987 Task Force Report on High Blood Pressure in Children and Adolescents. Pediatrics 98, 649-658.

6. World Health Organization (1995) Physical Status: The Use and Interpretation of Anthropometry. Technical Report Series no. 854. Geneva: WHO. 
7. Nobre MRC, Domingues RZL, Silva AR, Colugnati FAB \& Taddei JUAC (2006) Prevalence of overweight, obesity and life style associated with cardiovascular risk among middle school students. Rev Assoc Med Bras 52, 118-124.

8. Silva GAP, Balaban G \& Motta MEFA (2005) Prevalence of overweight and obesity in children and adolescents of different socioeconomic conditions. Rev Bras Saude Materno-Infantil (Recife) 5, 53-59.

9. Anjos LA, Castro IRR, Engstrom EM \& Azavedo AMF (2003) Growth and nutritional status in a probabilistic sample of schoolchildren from Rio de Janeiro, 1999. Cad Saude Publica 19, S171-S179.

10. Souza Leão SC, Araújo LMB, Moraes LTLP \& Assis AM (2003) Prevalence of obesity in school children from Salvador, Bahia. Arq Bras Endocrinol Metab 47, 151-157.

11. Berenson GS, Wattigney WA \& Tracy RE (1992) Atherosclerosis of the aorta and coronary arteries and cardiovascular risk factors in persons aged 6 to 60 years and studied at necropsy (The Bogalusa Heart Study). Am J Cardiol 70, $851-858$

12. The Pathobiological Determinants of the Atherosclerosis in Youth (PDAY) Research Group (1993) Natural history of aortic and coronary atherosclerosis lesions in youth: findings from the PDAY Study. Arterioscler Thromb 13, 1291-1298.

13. Instituto Brasileiro de Geografia e Estatística (2006) Consumer Expenditure Survey 2002-2003 - Analyses of Consumer Profiles According to Characteristics of the Reference Person. http://www.ibge.gov.br

14. Almeida SS, Nascimento PCBD \& Quaioti TCB (2002) Amount and quality of food advertisement on Brazilian television. Rev Saude Publica 36, 353-355.

15. Mendonça CP \& Anjos LA (2004) Dietary and physical activity factors as determinants of the increase in overweight/obesity in Brazil. Cad Saude Publica 20, 698-709. 